\title{
Excision of Second Branchial Cleft Cyst Via Retroauricular Approach without Assistance of Endoscopic or Robotic System
}

\author{
A Young Kim, Jin Hyun Ryu, Jin Ho Sohn, and Dongbin Ahn \\ Department of Otolaryngology-Head and Neck Surgery, School of Medicine, Kyungpook National University, Daegu, Korea
}

\author{
내시경이나 로봇 없이 시행되는 후이개 접근법을 통한 제2새열낭종 적출술 \\ 김아영 · 류진현 · 손진호 · 안동빈 \\ 경북대학교 의학전문대학원 이비인후-두경부외과학교실
}

\author{
Received September 2, 2016 \\ Revised November 16, 2016 \\ Accepted December 1, 2016 \\ Address for correspondence \\ Dongbin Ahn, MD \\ Department of Otolaryngology- \\ Head and Neck Surgery, \\ School of Medicine, \\ Kyungpook National University, \\ 130 Dongdeok-ro, Jung-gu, \\ Daegu 41944, Korea \\ Tel $+82-53-200-5781$ \\ Fax $+82-53-200-4524$ \\ E-mail godlikeu@naver.com
}

\begin{abstract}
Background and Objectives Traditionally, the surgical approach for the excision of second branchial cleft cysts involves performing a transverse cervical incision on the skin overlying the mass. Recently, there has been a significant interest on the cosmetic outcomes of this surgery, and it has been found that the retroauricular approach produces better results. The purpose of this study was to evaluate the feasibility of a retroauricular approach for the excision of second branchial cleft cysts without the assistance of endoscopic or robotic system.

Subjects and Method From August 2013 to May 2016, a total of 12 patients with second branchial cleft cysts underwent surgery for the excision of the cyst via retroauricular approach, which involved an incision along the retroauricular sulcus and hairline. The surgical outcomes, complications, and subjective satisfaction with incision scars were assessed.

Results In all 12 cases, the second branchial cleft cysts were removed successfully under direct vision and without the requirement of endoscopic assistance. The mean operation time was $80.3 \mathrm{~min}$ (range, 65-105 min). No significant complications were reported, such as skin flap necrosis, hematoma, seroma, or serious cranial nerve injury. The mean visual analogue scale score for subjective satisfaction with the incision scar was 8.8 (range, 7-10).

Conclusion The excision of second branchial cleft cysts via retroauricular approach without the assistance of endoscopic or robotic system is technically feasible and it provides a favorable cosmetic outcome.

Korean J Otorhinolaryngol-Head Neck Surg 2017;60(3):120-4
\end{abstract}

\section{서 론}

제2새열낭종(second branchial cleft cyst)은 가장 흔한 형태 의 새성기형으로, 주로 level II 영역의 무통성 경부 종물로 나 타나게 된다. ${ }^{1)}$ 드물게 감염으로 인해 심한 종창과 통증 등의 증상을 호소하는 경우도 있으나, 대부분의 경우 종물과 관련 된 불편감은 없거나 크지 않으며, ${ }^{2)}$ 그럼에도 불구하고 종물로 인한 외형적 문제로 인해 치료를 요하는 경우가 흔히 발생한 다. 제 2 새열낭종의 일차 치료는 수술적 제거로, 전통적으로 종
물의 위치에 해당하는 경부의 피부 절개를 통하여 낭종을 완 전히 적출하는 방식이 이용되었다. ${ }^{3)}$ 이러한 수술적 접근 방법 은 직접적인 수술 시야를 확보하여 낭종의 적출을 쉽게 하고, 주변의 신경이나 혈관 등 주요 구조물들을 안전하게 보존할 수 있는 방법임에는 틀림이 없으나, 종물로 인한 외형적 변형 대신 절개 흥터로 인한 외형적 문제를 여전히 남기게 되며, 이 는 환자 입장에서 제 2 새열낭종을 치료하는 가장 중요한 이유 중 하나가 외형적 문제의 해결이라는 점을 고려하였을 때, 치료 후 환자의 만족도를 저하시키는 주된 원인이 된다. 
최근에는 이러한 술 후 흥터에 관한 문제를 극복하고자 피 부 절개의 크기를 최소화하거나, 또는 그 위치를 잘 드러나지 않는 곳으로 옮기려는 노력이 커지고 있으며, 그중 후이개 접 근법(retroauricular approach)이 현재 가장 널리 사용되고 있 다. 후이개 접근법은 종물이 위치하는 경부의 피부에 절개를 가하는 기존 접근법 대신, 절개 부위를 이개 후방으로 옮겨 술 후 흥터가 이개와 모발에 의해 가려지도록 하는 방법으로, 제 2 새열낭종과 같은 양성 경부 종물의 제거나 갑상선 절제술, 그 리고 일부 선택적 경부 절제술 등에 이미 적용되고 있으며, 이 러한 경우 대부분 내시경이나 로봇을 이용하여 수술이 진행 되었다. ${ }^{4-6)}$ 하지만 제2새열낭종의 경우 그 중심이 항상 악하선 의 후방, 경동맥 공간의 외방, 그리고 흉쇄유돌근의 전내방에 위치하는 특징을 가지며, 이러한 전형적인 위치는 후이개 절개 부위로부터도 그리 멀지 않기 때문에 로봇이나 내시경 없이 적절한 피부 견인만으로도 충분한 수술 시야를 얻을 수 있다. 실제 후이개 절개법과 관련된 초기 연구에서는 제 2 새열낭종 을 포함한 level II 영역의 다양한 경부 종물을 로봇이나 내 시경을 사용하지 않고도 큰 무리 없이 제거하였음을 보고하 였다. ${ }^{23)}$ 이에 저자들은 본 연구를 통해 제2새열낭종 적출에 있어 내시경 및 로봇 없이 시행되는 후이개 접근법의 기술적 가능성을 살펴보고 그 결과를 평가해 보고자 하였다.

\section{대상 및 방법}

\section{대 상}

본 연구는 2013년 8월에서 2016년 5월까지 후이개 접근법을 통해 시행된 12 예의 제 2 새열낭종 절제술을 대상으로 하였으 며, 저자들이 속한 기관 임상연구심의위원회의 연구승인하 에 전향적으로 진행되었다(IRB: 201604020).

모든 예에서 수술 전 경부 초음파 및 세침흡인 검사, 경부 전산화단층촬영을 시행하여 제 2 새열낭종 외의 가능성을 배 제하고, 구체적인 종물의 위치와 크기를 파악하였다. 전체 환 자의 평균 나이는 29.2세(17 47세)였으며, 12명의 환자 모두

Table 1. Baseline patients characteristics

\begin{tabular}{ll}
\hline \multicolumn{1}{c}{ Variables } & Patients $(\mathrm{n}=12)$ \\
\hline $\begin{array}{l}\text { Age (years) } \\
\text { Sex }(\%)\end{array}$ & 29.2 (range, 17-47) \\
$\quad$ Male & $0(0.0)$ \\
Female & $12(100.0)$ \\
Mass size $(\mathrm{cm})$ & 4.2 (range, 3.5-5.2) \\
Location of the mass (\%) & \\
Confined to level II & $9(75.0)$ \\
Extended to level III & $3(25.0)$ \\
Previous infection history $(\%)$ & $4(33.3)$ \\
\hline
\end{tabular}

여자였다. 술 전 영상학적 검사의 축상면(axial view)에서 확인 된 낭종의 평균 크기는 $4.2 \mathrm{~cm}(3.5 \sim 5.2 \mathrm{~cm})$ 였으며, 그 범위 가 level II에 국한된 경우가 9예(75.0\%), level III까지 확장된 경우가 3예(25.0\%)였다. 4명(33.3\%)의 환자에서는 수술 전 낭 종의 감염으로 인해 약물 및 흡인 치료를 받은 병력이 있었 다(Table 1).

\section{절개 방법 및 수술 술기}

모든 수술은 전신마취하에 한 명의 두경부 외과의에 의해 시행되었다. 로봇이나 내시경 없이 시행되는 후이개 접근법을 통한 수술의 기술적 가능성을 평가하기 위해 모든 수술은 우 선 2.5 배 확대경을 착용한 상태의 직접 시야에서 시작되었다. 그리고 만약 수술 시야 노출에 어려움이 있거나, 낭종을 확실 하고 안전하게 제거하기 위해 내시경이 필요하다고 생각되면 언제든지 내시경수술로의 전환이 가능하도록 내시경 및 관련 수술 장비를 모두 준비해 둔 상태에서 수술을 진행하였다.

수술을 위해 환자는 경부를 신전시킨 앙와위에서 머리를 병변의 반대측으로 돌리는 자세를 취하였다. 피부 절개 전 $0.5 \mathrm{~cm}$ 폭의 후이개 부위 모발을 짧게 깎아 절개 부위의 시야 가 용이하도록 하였다. 피부 절개는 후이개구(retroauricular sulcus)의 하단에서 시작하여 상방으로 외이도 높이의 후이개 구 중간 지점까지 진행한 다음, 후하방으로 방향을 바꾸어 모발선을 따라 이어지도록 하였다(Fig. 1). 피부 절개 후 흥쇄 유돌근의 표면을 따라 전하방으로 접근하였으며, 광경근이 확인되는 지점부터는 광경근의 아래쪽 표면을 따라 낭종의 전방 경계까지 광경근하 피부 피판을 거상하였다. 이 과정에 서 대이개신경과 안면신경의 하악연분지를 손상시키지 않도

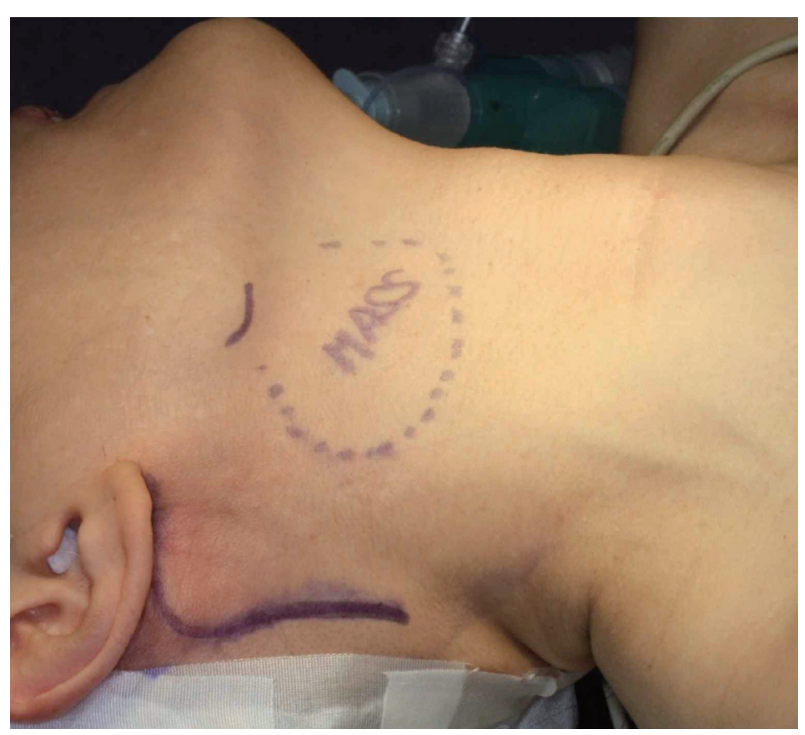

Fig. 1. A skin incision for the retroauricular approach was made along the retroauricular sulcus and hairline. 
록 각별한 주의를 기울였다. 피부 피판 거상이 완료되면 훙 쇄유돌근의 앞쪽 경계를 박리하여 낭종의 후하방 부위가 노 출되도록 하였다(Fig. 2). 이후 낭종을 후하방으로 견인하면 서 피막외 박리(extracapsular dissection)를 진행하여 주변 조 직으로부터 낭종을 분리하였으며, 이 과정에서 낭종의 피막 이 파열되지 않도록 주의를 기울였다(Fig. 3). 낭종의 완전 적 출 후 해당 공간에는 음압 배액관을 거치하고, 절개 부위를 봉 합하였다.

\section{평가 항목}

마취 시작부터 종료까지의 총 수술 시간, 수술 중 직접 시야 에서의 수술 진행 어려움으로 인한 내시경 수술로의 전환, 의 도치 않은 낭종의 파열, 수술 후 총 배액량 및 배액관의 거치 기간, 그리고 술 후 입원기간에 대해 평가하였다. 술 후 합병증 으로는 피부 피판의 괴사, 혈종, 장액종, 입꼬리 움직임의 약 화, 척수부신경이나 설하신경 등의 뇌신경 손상, 귓볼의 감각 둔화, 그리고 절개부위의 흥터 상태 등에 대해 확인하였으며, 술 후 3개월째 절개 부위에 대한 환자의 주관적 만족도를 visual analog scale을 이용하여 0점에서 10점까지 측정하였다.

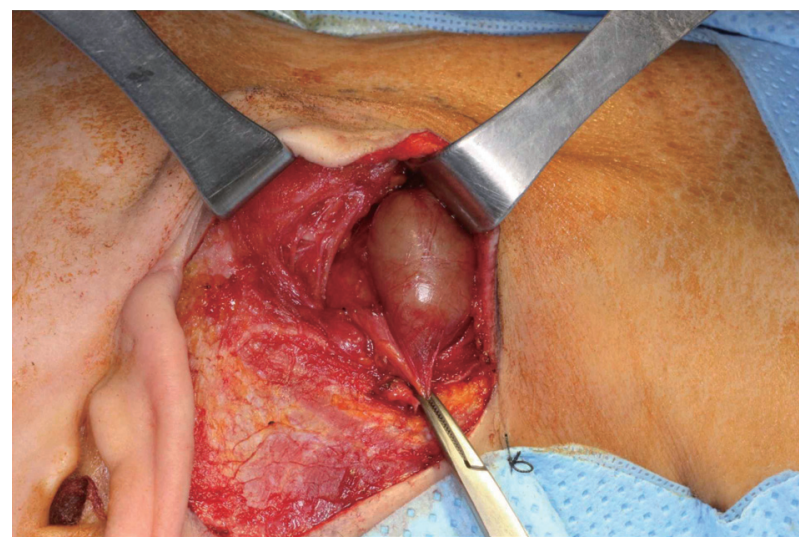

Fig. 2. The mass was exposed after elevation of the subplatysmal skin flap and separated from the anterior border of the sternocleidomastoid muscle.

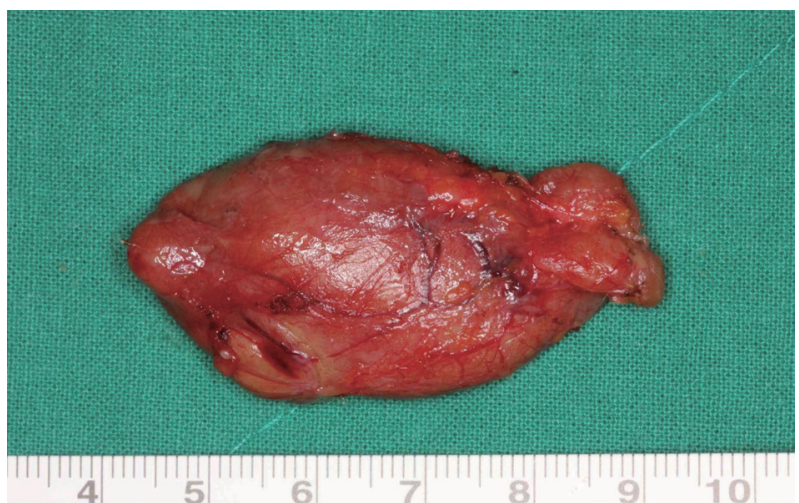

Fig. 3. The mass was removed completely without tumor spillage.

\section{결 과}

\section{수술 결과}

마취 시작부터 종료까지의 총 수술 시간은 평균 80.3분(65 105 분)이었으며, 수술 시간을 감염 여부에 따라 구분해 보았 을 때, 수술 전 낭종의 감염이 없었던 8예에서의 평균 수술 시 간은 75.6분(65 90분), 감염이 있었던 4예에서는 평균 89.8분 (72 100분)으로 약 14분의 차이를 보였다. 전체적으로는 해 당 접근법에 대한 술자의 경험이 축적됨에 따라 수술 시간이 점차 단축되는 경향을 보여 처음 6예에서의 평균 수술 시간은 89.2분(75 105분)이었으나 마지막 6예에서의 평균 수술 시간 은 71.5분(65 82분)이었다(Fig. 4). 수술 중 시야 확보를 위한 내시경적 수술로의 전환이 필요했던 경우는 없었으며, 모든 예 에서 내시경의 도움 없이 직접 시야하에서 성공적으로 수술이 진행되었다. 수술 중 낭종의 견인 등으로 인해 의도치 않은 낭 종의 파열이 발생한 경우는 없었다. 수술 후 총 배액량은 평균 $40.3 \mathrm{~mL}(25 \sim 52 \mathrm{~mL})$ 였으며 배액관의 평균 거치 기간은 2.9 일(2 4일)이었다. 술 후 평균 입원 기간은 3.4일(2 5일)이었다 (Table 2).

\section{술 후 합병증}

전체 12 명의 환자 중 상처와 관련된 피부 피판 괴사와 혈종, 장액종 등의 합병증이 발생한 경우는 한 예도 없었으며, 안면 신경의 하악분지나 척수부신경, 설하신경 등의 뇌신경 손상이

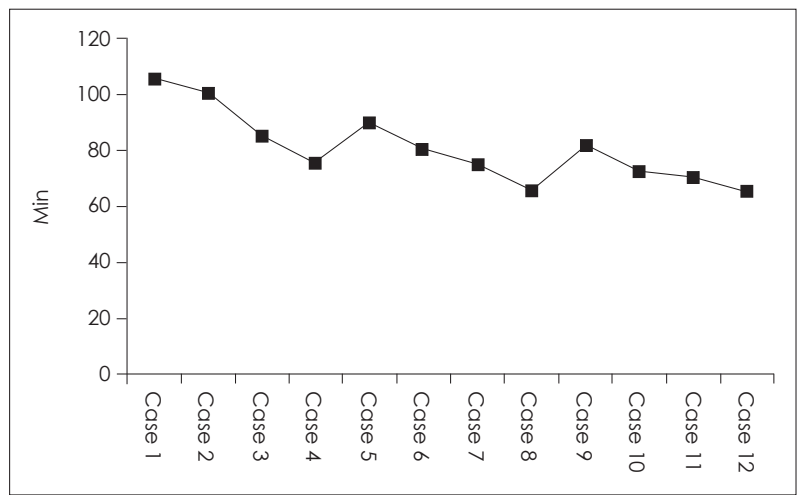

Fig. 4. Operation time of excision of second branchial cleft cyst via retroauricular approach in 12 cases.

Table 2. Surgical outcomes

\begin{tabular}{ll}
\hline \multicolumn{1}{c}{ Variables } & Patients $(\mathrm{n}=12)$ \\
\hline Operation time $(\mathrm{min})$ & $80.3($ range, 65-105) \\
Requirement of endoscopic assistance & $0(0.0 \%)$ \\
Inadvertent mass spillage & $0(0.0 \%)$ \\
Drainage amount $(\mathrm{mL})$ & $40.3($ range, 25-52) \\
Drainage duration (days) & 2.9 (range, 2-4) \\
Postoperative hospital stay (days) & 3.4 (range, 2-5) \\
\hline
\end{tabular}


Table 3. Postoperative complications

\begin{tabular}{lc}
\hline \multicolumn{1}{c}{ Variables } & Patients $(\mathrm{n}=12)$ \\
\hline Skin flap necrosis & $0(0.0 \%)$ \\
Hematoma & $0(0.0 \%)$ \\
Seroma & $0(0.0 \%)$ \\
Postoperative mouth angle weakness & $0(0.0 \%)$ \\
Cranial nerve injury & $0(0.0 \%)$ \\
Transient numbness of the earlobe & $2(16.7 \%)$ \\
Hypertrophic scar & $1(8.3 \%)$ \\
Visual analogue scale score for subjective & $8.8(7-10)$ \\
satisfaction with incision scar 3 months & \\
after surgery & \\
\hline
\end{tabular}

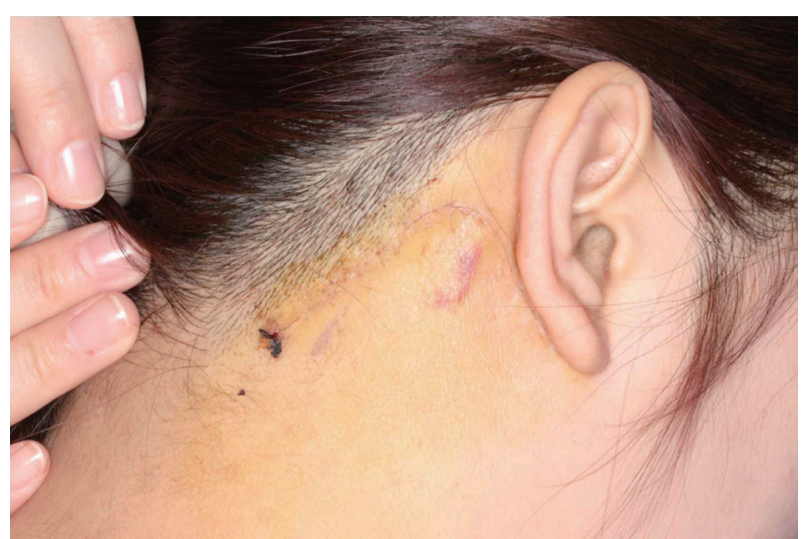

Fig. 5. Photograph obtained immediately after removal of stitches on the seventh postoperative day shows complete healing of the incision wound, which can be concealed by the patient's hair and the auricle.

발생한 경우도 없었다. 수술 후 귓볼 감각의 둔화는 2예 (16.7\%)에서 발생하였으나, 술 후 3개월 이내에 모두 회복되었 다. 1 예에서는 경한 비후성 반흔이 관찰되었으나, 주관적인 불편감을 호소하거나 외형적인 문제를 일으키지 않아 특별한 치료 없이 경과 관찰하였다. 수술 후 3개월째 visual analog scale을 이용하여 평가한 절개 방법 및 수술 상처에 대한 주관 적 만족도는 평균 8.8점(7 10점)이었다(Table 3, Fig. 5).

\section{고 찰}

이번 연구는 후이개 접근법을 통한 제 2 새열낭종 적출술이 내시경이나 로봇의 도움 없이도 충분히 기술적으로 가능함 을 보여 주었다. 지난 수년간 내시경이나 로봇 시스템의 도입 이 증가함에 따라, 선천성 경부 종물, 악하선, 그리고 림프절 수술 등에 대한 후이개 접근법이 활발히 활용되어 왔으며, 최근에는 광범위 경부 림프절 곽청술에도 내시경이나 로봇 시 스템을 이용한 후이개 접근법이 적용되었다. $4.6,7)$ 하지만 내시 경이나 로봇을 이용하여 후이개 접근법을 통한 경부 림프절
곽청술을 시행했던 문헌들을 살펴보면, level II, III 경부 영 역에 대한 수술은 내시경이나 로봇의 도움 없이 직접 시야하 에 이루어졌다고 기술하고 있어, 후이개 접근법을 통한 level II, III 영역의 수술에서 내시경이나 로봇의 사용이 필수조건 이 아님을 간접적으로 시사하고 있다. ${ }^{8-10)}$ 실제 level II, III 영 역의 제 2 새열낭종을 대상으로 한 본 연구에서도 전체 12 명의 환자 모두에서 특별한 추가 기구 없이 직접 시야만으로도 후 이개 접근법을 통해 성공적으로 종물을 제거할 수 있었으며, 수술 중 완전한 그리고 안전한 수술을 위해 내시경 수술로의 전환이 필요했던 경우는 한 예도 없었다. 사실, 내시경과 로봇 시스템은 모든 의료기관에서 사용 가능한 것은 아니며, 또한 의료진이 해당 시스템을 이용하여 능숙한 수술을 시행하기 위해서는 추가적인 훈련 및 어느 정도의 학습 곡선(learning curve)이 형성될 시간이 필요하다. 또한 환자의 입장에서는 후이개 접근법을 통한 수술에서 내시경이나 로봇 시스템 사 용에 따른 추가적인 비용 발생이 매우 부담스러울 수 있다. 따라서, 본 연구에서 보여준 것처럼 후이개 접근법을 통한 제 2새열낭종 수술이 내시경이나 로봇 시스템 없이도 충분히 가능하다는 것은, 내시경이나 로봇 수술에 익숙하지 않은 의 료진 및 추가적인 비용의 부담 없이 미용적 수술 접근 방법 을 원하는 환자 모두에게 의미 있는 결과로 생각된다. 하지만 수술 자체의 가능 여부를 떠나 내시경이나 로봇을 사용하는 경우에는 보다 확대된 시야에서의 수술이나 직접 시야만으 로는 수술 시야 확보가 불가능한 영역으로의 추가적인 접근 이 가능해지고, 또한 직접 시야에서의 수술에 비해 후이개 부 위의 피부 절개 길이를 줄일 수 있는 장점이 있을 것으로 생 각된다.

본 연구에서는 수술 시간을 마취 시작부터 마취 종료까지 로 정의하였을 때, 평균 $4.2 \mathrm{~cm}$ 크기의 종물을 제거하는 데 평균 80 분가량의 수술 시간이 소요되었다. 이는 Chen과 $\mathrm{Fang}^{2)}$ 이 직접시야 하에서 후이개 접근법을 통한 제 2 새열낭 종의 수술법에 대한 연구에서 보고한 1.5 시간의 수술 시간과 유사한 것으로, Song 등1ㅣㅇㅣ 로봇을 이용하여 후이개 접근법 을 통한 제2새열낭종 수술 연구에서 보고한 130 155분의 수술 시간에 비해서는 약 1 시간가량 짧은 것이었다. 다만 수 술 전 감염 병력이 있는 경우 수술 시 종물과 주변 조직의 박 리가 용이하지 않은 경향이 있었으며, 이로 인해 감염의 병력 이 없는 경우에 비해 수술 시간이 다소 길어지는 것을 확인할 수 있었다. 하지만 본 연구에서 그 차이는 약 14 분가량으로, 이전 감염의 병력이 후이개 접근법 사용의 금기로 여겨질 만 큼 수술 시간의 연장을 초래하지는 않았다. 또한 이번 연구 에서 수술을 담당한 두경부 외과의는 이전에 후이개 접근에 대한 경험이 없었음에도 불구하고, 본 연구에 포함된 모든 
경우에 있어 기술적으로 큰 어려움이 없이 수술을 진행할 수 있었으며, 수술 시간 역시 술자의 경험이 축적되면서 점차 단 축되는 경향을 보였다.

수술 후 경과에 있어서도 전체 배액량이나 배액관의 거치 기간, 그리고 퇴원 시기 등의 항목에서 기존의 고식적인 수술 법이나 내시경, 로봇을 이용한 연구 등의 결과와 유사한 결과 를 보였으며, 임상적으로 의미 있는 합병증 역시 발생하지 않 았다. ${ }^{5,6,11)}$

본 연구에서의 술 후 흉터에 대한 만족도는 평균 8.8점이었 는데, 이는 이전의 연구에서 고식적인 피부 절개법을 사용한 경우의 흥터에 대한 만족도가 평균 5점가량으로 보고된 것을 고려하면 매우 높은 흥터 만족도로 생각되며, ${ }^{7,21}$ 측정 방식에 는 다소 차이가 있지만 내시경이나 로봇을 이용하여 후이개 접근법을 통해 수술을 시행한 경우의 흥터 만족도와 비교하 여도 큰 차이를 보이지 않았다. ${ }^{4,513)}$ 사실 술 후 흉터에 있어서 는 본 연구에서처럼 직접 시야에서 수술을 시행한 경우와 내 시경이나 로봇을 이용하여 수술을 시행한 경우 모두에서 동 일하게 후이개 접근법을 통해 수술이 시행되기 때문에 내시 경이나 로봇 이용 여부에 따라 환자의 만족도가 크게 다를 만한 이유는 없을 것으로 생각된다. 물론 앞서 언급하였듯이 내시경이나 로봇을 사용하여 후이개 접근법을 시행한 경우 육안적 수술에 의존하는 경우보다는 상대적으로 피부 절개 의 길이를 줄일 수 있을 것으로 생각되나, 후이개 피부 절개 자체가 이개 및 모발에 의해 대부분 가려지기 때문에 해당 부위의 피부 절개를 줄이는 것이 환자의 술 후 흥터 만족도 에 크게 영향을 주지는 않을 것으로 판단된다.

이번 연구의 가장 큰 제한점은 연구기간 동안 전향적으로 모집한 환자의 수가 12 명으로 적기 때문에 이들 환자들을 고 식적 피부 절개를 사용한 군과 후이개 접근법을 사용한 군으 로 나누어 비교 연구하지 못하였다는 점이다. 하지만 이러한 단점에도 불구하고 후이개 접근법을 통한 새열낭종 적출술 과 관련된 연구들이 대부분 10 명 이하의 환자를 대상으로 한 것임을 고려하였을 때, ${ }^{2,4,6,12)} 12$ 명이라는 환자 수는 현재까지 단일 술자에 의해 시행된 연구 중 가장 많은 환자를 포함하는 것이며, 따라서 그 기술적 가능성에 대한 평가는 충분히 가치 있을 것으로 생각되는 바이다.

결론적으로 직접 시야에서 시행되는 후이개 접근법을 통한 제2새열낭종 적출술은 특별한 합병증 발생 없이 기술적으로
충분히 가능하였으며, 환자에게 매우 높은 흥터 만족도를 제 공할 수 있었다. 본 연구를 바탕으로 내시경이나 로봇 시스템 의 활용이 어려운 기관에서도 후이개 접근법을 통한 미용적 경부 수술이 보다 활성화 될 수 있을 것으로 생각되며, 환자 들 역시 추가적인 비용 부담 없이 제 2 새열낭종 제거에 있어 후 이개 접근법을 선택할 수 있을 것으로 사료되는 바이다.

\section{REFERENCES}

1) Koeller KK, Alamo L, Adair CF, Smirniotopoulos JG. Congenital cystic masses of the neck: radiologic-pathologic correlation. Radiographics 1999;19(1):121-46; quiz 152-3.

2) Chen WL, Fang SL. Removal of second branchial cleft cysts using a retroauricular approach. Head Neck 2009;31(5):695-8.

3) Roh JL, Yoon YH. Removal of pediatric branchial cleft cyst using a retroauricular hairline incision (RAHI) approach. Int J Pediatr Otorhinolaryngol 2008;72(10):1503-7.

4) Lee HS, Lee D, Koo YC, Shin HA, Koh YW, Choi EC. Endoscopic resection of upper neck masses via retroauricular approach is feasible with excellent cosmetic outcomes. J Oral Maxillofac Surg 2013;71 (3):520-7.

5) Lee HS, Kim D, Lee SY, Byeon HK, Kim WS, Hong HJ, et al. Robot-assisted versus endoscopic submandibular gland resection via retroauricular approach: a prospective nonrandomized study. Br J Oral Maxillofac Surg 2014;52(2):179-84.

6) Park YM, Byeon HK, Chung HP, Rho KJ, Kim SH. Robotic resection of benign neck masses via a retroauricular approach. J Laparoendosc Adv Surg Tech A 2013;23(7):578-83.

7) Roh JL. Retroauricular hairline incision for removal of upper neck masses. Laryngoscope 2005;115(12):2161-6.

8) Zhou S, Zhang C, Li D. Approaches of robot-assisted neck dissection for head and neck cancer: a review. Oral Surg Oral Med Oral Pathol Oral Radiol 2016;121(4):353-9.

9) Kim WS, Byeon HK, Park YM, Ha JG, Kim ES, Koh YW, et al. Therapeutic robot-assisted neck dissection via a retroauricular or modified facelift approach in head and neck cancer: a comparative study with conventional transcervical neck dissection. Head Neck 2015;37(2):249-54.

10) Park YM, Holsinger FC, Kim WS, Park SC, Lee EJ, Choi EC, et al. Robot-assisted selective neck dissection of levels II to $\mathrm{V}$ via a modified facelift or retroauricular approach. Otolaryngol Head Neck Surg 2013; 148(5):778-85.

11) Song CM, Ji YB, Kim KR, Tae K. Robot-assisted excision of branchial cleft cysts using a postauricular facelift approach. Auris Nasus Larynx 2015;42(5):424-7.

12) Roh JL, Yoon YH, Park CI. Removal of nonthyroidal neck masses with improved cosmetic outcomes in skin-lifting surgery. Otolaryngol Head Neck Surg 2006;135(3):463-8.

13) Chen J, Chen W, Zhang J, He F, Zhu Z, Tang S, et al. Modified endoscope-assisted partial-superficial parotidectomy through a retroauricular incision. ORL J Otorhinolaryngol Relat Spec 2014; 76(3):121-6. 